\title{
Stonehenge as an Astronomical Instrument
}

\author{
by A. P. Trotter
}

$\mathrm{T}$ HE astronomical controversy about Stonehenge may perhaps be approached from an impartial view of one who is neither an archæologist nor an astronomer, who offers no new or original observations, and proposes to examine facts rather than to discuss theories.

Sir Norman Lockyer was one of those who held that many Egyptian and Greek buildings were set so that they faced certain points on the horizon at which the sun or some bright star arose. But the buildings do not face these directions exactly, and the suggestion is that the discrepancies are due to a well recognized astronomical principlethat the points of rising and setting gradually move on the horizon; and the rate of motion being known, the date of the building may be ascertained.

We are faced, at the outset, by two suggestions : that these structures were intentionally placed in these directions, and that they were built at these dates. The first is supported by the facts,-supported, not rigorously proved, - and the second is open to verification where historical data are forthcoming.

As when an archæologist beginning to excavate a site, digs through stones, mud, rubbish, and perhaps rock, and throws on one side all that contains nothing of worth to him, so he has to work through vague guesses, conjectures, old wives' tales, and even profound theories, and accept or reject them in his search for pertinent facts. One man's rubbish may be another man's treasure. Old wives' tales and traditions accurately compared and intelligently related may form a contribution to folk-lore, to the history of mankind, and to anthropological and ethnological science. On one solitary fact a wonderful edifice of speculation may be raised; on the other hand, a patient accumulator of facts may labour for years, and have no more capacity for making any advancement in knowledge than if he had collected postage stamps. 


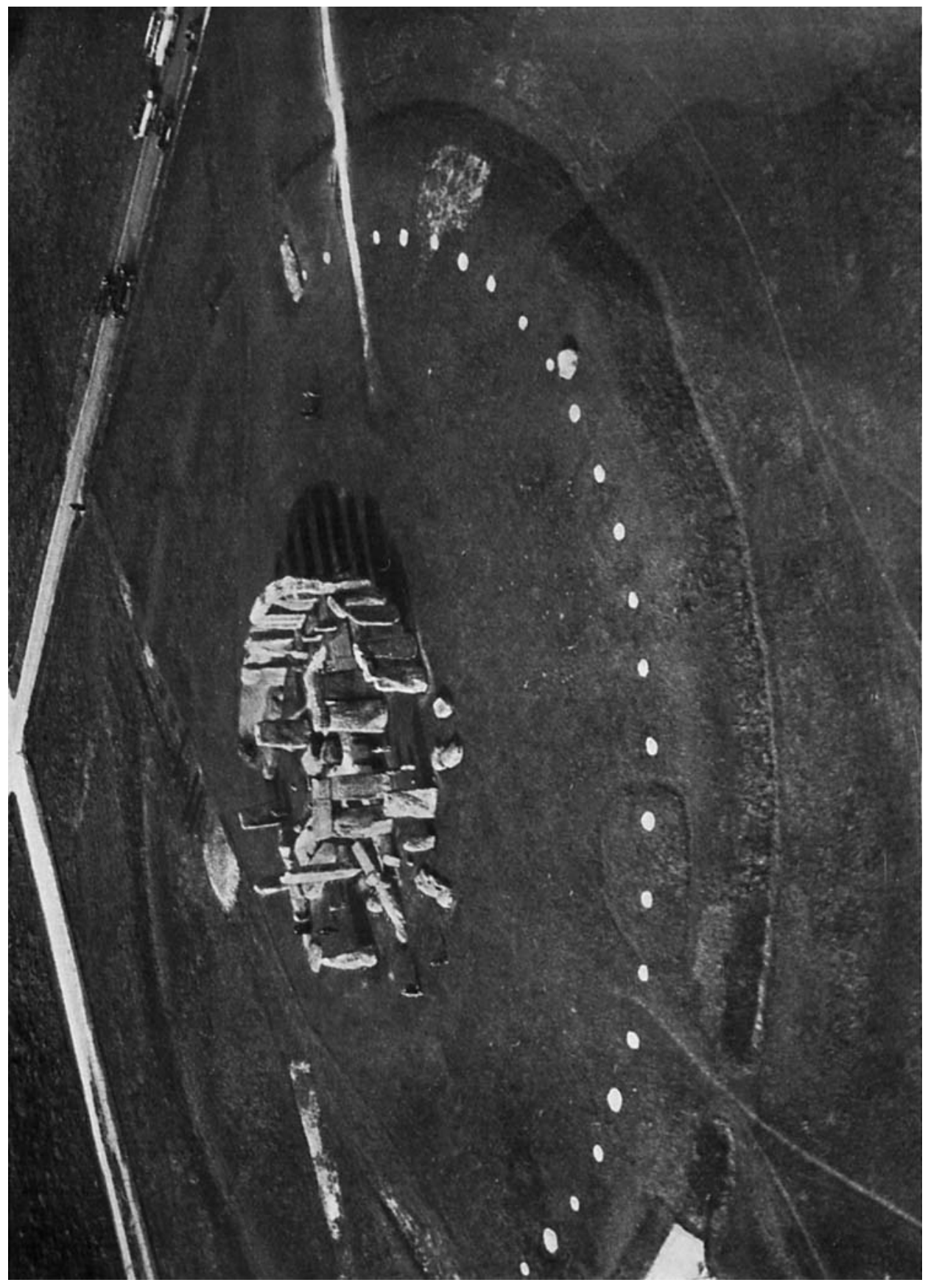

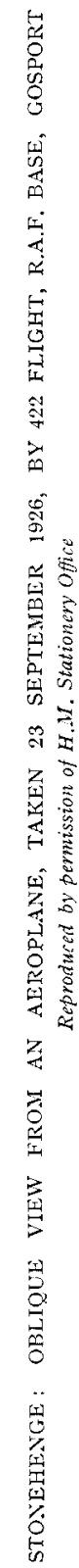

facing $p .42$ 


\section{STONEHENGE AS AN ASTRONOMICAL INSTRUMENT}

The arrangement of the stones, the causeway of approach, and the so-called avenue of Stonehenge face towards the north-east, and more particularly towards the most northerly point on the horizon at which the sun rises at midsummer. On this general fact has been based the theory that Stonehenge was a temple for sun worship. Neither in Lockyer's Stonehenge and other British Stone Monuments, though it contains chapters on "Where did the British worship originate," and on "A short History of Sun-Temples," nor in any other writings that I have seen, can I find evidence of any institutional sun-worship in Britain, or sufficient proof that Stonehenge or any other stone circle was used as a place for public worship. There seems to be nothing but vague conjecture about the religion of the inhabitants of Britain until the time of the Druids, and the interval between the building of Stonehenge and our earliest account of the Druids is perhaps some 2,000 years. It may be that " going to church" did not play an important part in the religion of those days.

The popular tradition is, that on the longest day of the year the sun, as seen from the interior of Stonehenge, rises exactly over the Heel stone; and "therefore" Stonehenge was a temple for sun-worship. In the spring, the sunrise is in the east, and as summer comes on, its place on the horizon moves, at first quickly, and then more slowly towards the north, and it creeps up to the northernmost point which is reached on about 2I June, and after that it returns southwards. What is exactly meant by its " place of rising " will be discussed later. The tradition cannot be traced back for more than about 150 years, and it is certain that the sun never did rise over the Heel stone when observed at midsummer from the direction chosen by Lockyer, and will not do so until about 500 years hence. (By a slip of the pen, $\mathrm{Mr}$ E. H. Stone puts this at 1,000 years) ${ }^{1}$ On that sunrise morning, may Stonehenge be there as it is to-day, and may all the deserted buildings and rusty derelict sheds in its neighbourhood have utterly disappeared !

As an astronomical instrument, Stonehenge consists of a pair of "sights" like those of a rifle. The fore-sight is the pair of stones (nos. 30 and I) forming the entrance. The back-sight was the pair of stones forming the largest trilithon (that is a set of two upright stones and a lintel or cross stone resting on them), but of these only one, the tallest of all the stones (no. 56) is standing. For many years it was leaning, and was set upright in rgor. Its companion (no. 55) fell before

1 E. H. Stone, The Stones of Stonehenge, (1924), p. 130. 


\section{ANTIQUITY}

Stonehenge attracted the notice of antiquaries in the seventeenth century. There was another pair of stones, forming part of the outer circle, but only one of this pair (no. 16) remains, and it was not so important a back-sight as the great trilithon. (Fig. I).

When Lockyer made his investigations in 1901 , the great stone (no. 56) was still leaning, and it is possible that he considered that on this account it was of no great value for his purpose, although it was leaning in the direction of the entrance or the pair of stones which may be called the fore-sight. The Heel stone, about 205 feet from the entrance, was obviously no use as a fore-sight, it is too much to the right. In order to see it set midway in the entrance, you must stand with your back to the great stone, and at about six inches from its right hand (south-east) side.

Lockyer disregarded the stones altogether, and chose to adopt as his line of sight or axis the alignment of part of the indistinct earthwork called the avenue. This irregular earth-work, unnoticed by visitors whose attention has not been called to it, can be traced for a considerable distance, and photographs taken from the air show it curving to the right and ending at the river Avon. Mr Stone has examined it for $\mathrm{I}, 290 \mathrm{ft}$., and has made measurements over $750 \mathrm{ft}$. of its length, and considers that the true centre line cannot be determined with certainty until further excavations are made. It should be observed, however, that the direction, and not the centre line, is what Lockyer wanted. He seemed satisfied with it, and placed two pegs $140 \mathrm{ft}$. apart near the beginning, and four others averaging roo ft. apart towards the northeast. The discrepancy between the two directions only amounted to one in 620 , or, as he states it, 5 minutes 40 seconds of angle. He took the mean of the two directions as his line of sight.

I shall refer to this again later, but I prefer to deal with Stonehenge itself for the following reason given by $\mathrm{Mr}$ Stone in his book :- "The Axis of the main structure of Stonehenge as erected by the builders is a line passing midway between the stones nos. 56 and 55 of the central trilithon, and midway between the stones 30 and I of the outer circle." "It is obvious" writes Mr Stone, and there I agree with him, "that the term "Axis of Stonehenge' would be meaningless as applied to any other line." 1

The difficulty at once arises that stone no. 55 has fallen, and though the great stone no. $5^{6}$ is probably within an inch or two of its original

I Op. cit. p. I31. 


\section{STONEHENGE AS AN ASTRONOMICAL INSTRUMENT}
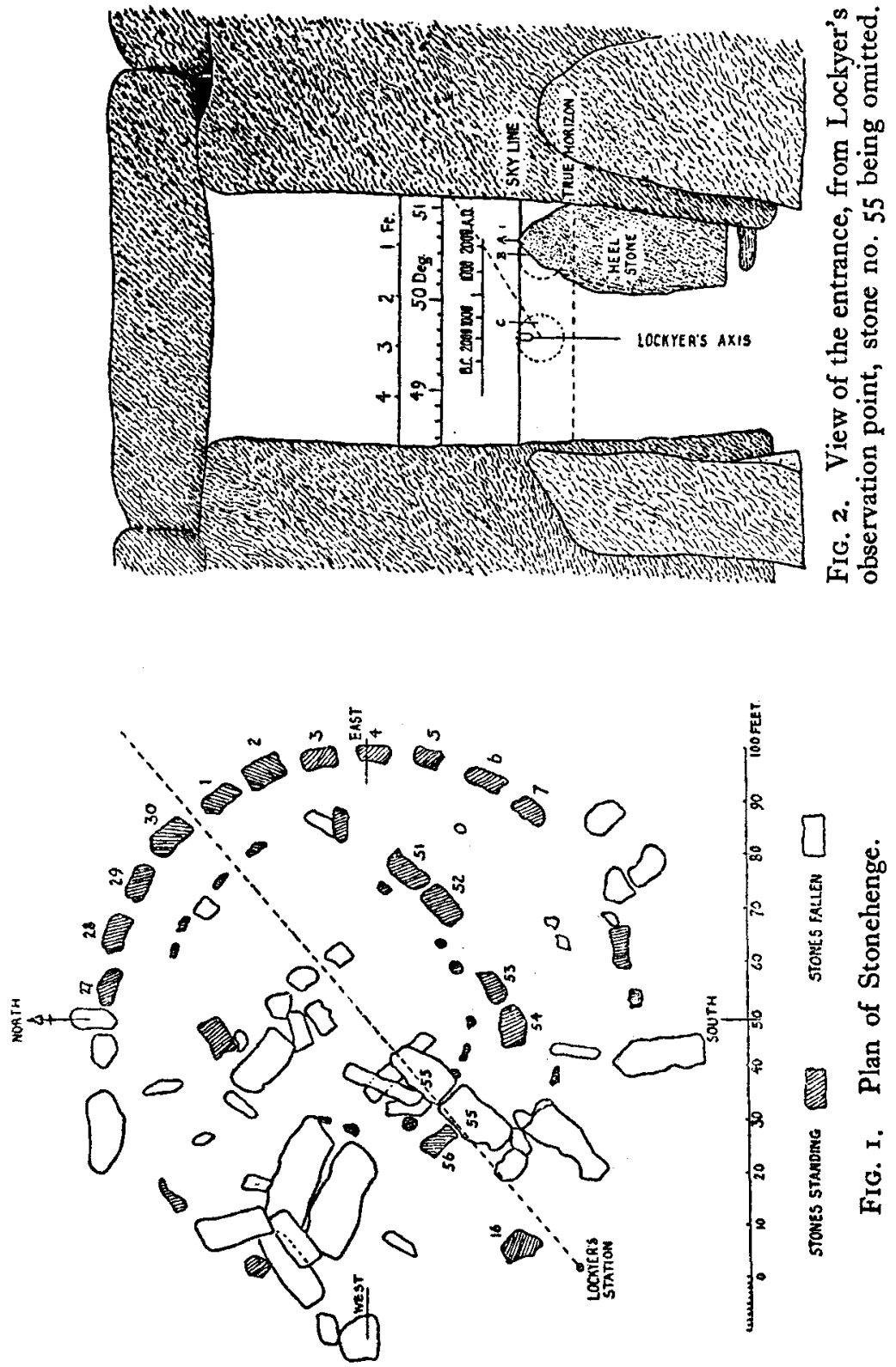


\section{ANTIQUITY}

position, another guess must be made about no. 55. No. 56 was set upright after Lockyer's investigations had been made, but before his book on Stonehenge was written. By comparison with the two perfect trilithons (nos. 5I-52, and 53-54) and by measurement of the mortice holes of the fallen lintel, he considered that his avenue axis or line of sight passed I I inches from the south-west side of no. 56. Mr Stone has made a careful examination of this matter and concludes that the distance between no. 55 and no. 56 was not less than $2 \mathrm{ft} .6$ ins., and taking the mean, suggests that the axis passes 18 ins. to the right of no. $5^{6}$, with a possible error of plus or minus 3 ins. Prof. Sir W. M. Flinders Petrie estimated that the distance between nos. 55 and 56 was only 12 ins.

An examination of the two complete trilithons shows that they are considerably weathered, and the mean distance between the uprights nos. 53 and 54 at $5 \mathrm{ft} .8$ ins. from the ground (the height of the eye), is about 15 ins., and between nos. $5^{1}$ and 52 about Io ins. For this reason, Lockyer's suggestion of I I ins. (that is, half a distance between the stones of 22 ins.) seems to be preferable to Mr Stone's estimate of $\mathrm{I} 8$ ins.; but this is no great matter. As a fore-sight, the business parts of the stones are at eye level. Where is our eye level ? This depends on the spot from which the astronomical observations are to be made. The centre of the circle will not do, we cannot aim from between the sights. Lockyer's station is not very conveniently described as " at a distance of $6 \mathrm{I} \mathrm{ft}$. to the south-west of the centre of the temple." (He assumed that it was a temple for sun-worship). I find this to be about $33 \mathrm{ft}$. 8 ins. from the south-west face of the great stone no. 56 , or $7 \mathrm{ft}$. beyond no. 16 , a solitary survivor in this direction of the stones of the outer circle. Standing here, with an eye-height of $5 \mathrm{ft} .8$ ins., and looking through the entrance, the ground line of the houses which may be taken as the sky-line horizon formed by Lark Hill crosses the stones nos. 30 and $\mathrm{I}$ at about $6 \mathrm{ft}$. $\mathrm{I}$ in. above ground level, and at this height a measuring rod $5 \mathrm{ft} .2$ ins. long can be sprung in between them, but owing to irregularities their effective distance apart is $5 \mathrm{ft}$. It may be significant that they are fairly plumb in their upper half, but have considerable batter or taper in the lower half. The great stone no. 56 is to all intents and purposes plumb on its south-east side.

Lockyer, having ignored the stones, was at great pains to define his axis along the direction of the avenue. He uses the term azimuth. This is an astronomical expression having exactly the same meaning 


\section{STONEHENGE AS AN ASTRONOMICAL INSTRUMENT}

as a surveyor's or a sailor's " bearing." Azimuth is measured as so many degrees, minutes and seconds from some zero standard bearing. For example, so many degrees east of north. If north is o degrees, then north-east is N. $45 \mathrm{E}$., that is, the azimuth is 45 degrees east of north. A magnetic compass corrected for the regular annual variation (about I6 degrees west at present), and for any local variation, is generally sufficient for the sailor, but it is not nearly accurate enough for the present purpose. To fix the direction, Lockyer took observations of the North Star and the sun, making, of course the proper corrections. He took also the azimuth or bearing of the spire of Salisbury Cathedral with a theodolite, and found this to be 9 degrees 8 minutes of angle east of south. The object of observing the spire was to enable him to use the Ordnance map as a check. The spire can be seen from Stonehenge on a clear day and by keen sight, or with a field glass. The mean of the two directions of the avenue gave an azimuth of N. 49 deg. $35 \mathrm{~min}$. $5 \mathrm{I} \mathrm{sec.} \mathrm{E.} \mathrm{Plotting} \mathrm{this} \mathrm{on} \mathrm{a} \mathrm{map} \mathrm{he} \mathrm{found} \mathrm{it} \mathrm{passed} \mathrm{close}$ to the top of Sidbury Hill, which is not visible from Stonehenge. $\mathrm{He}$ adopted this Sidbury Hill azimuth N. 49 deg. 34 min. 18 sec. E. as his final axis. Lockyer considered that this difference in azimuth was negligible, and Sidbury Hill could easily be referred to on a map. A sailor would say that the bearing was between N.E. and N.E. by E., or about $4 \frac{1}{2}$ points east of north. So far for his axis or line of sight.

The next thing was to observe the sunrise. This was done on the morning of 25 June I901, by Mr Howard Payn, after four unsuccessful mornings. The sunrise point is so nearly stationary at this time of year that the difference (owing to being four days late) is negligible. Some fixed point had to be chosen on the horizon, for the pegs set out along the avenue would not be visible from the observing point. The tip of the Heel stone most conveniently lent itself for the purpose (A, fig. 2).

It might be said that the process of sunrise is not complete until the whole of the sun can be seen. From an astronomical point of view, the moment of sunrise is when the disc of the sun is cut in half by the true horizon ; and again, the moment of sunrise may be said to be that at which the first gleam appears. Practically, Mr Payn allowed enough of the sun to rise to enable him to measure the exact middle of it with his theodolite. It was 2 minutes of angle or about one-sixteenth of its diameter above the skyline of Lark Hill. (B, fig. 2). The angular distance was found to be $8 \mathrm{~min}$. $40 \mathrm{sec}$. north of the tip of the Heel stone, or an azimuth of N. 50 deg. $30 \mathrm{~min}$. $54 \mathrm{sec}$. E. This is $5^{6} \mathrm{~min}$. 


\section{ANTIQUITY}

$36 \mathrm{sec}$. east of Lockyer's axis, and on this difference his theory of the date of the building of Stonehenge is founded.

As such angular measurements may be unfamiliar to many of my readers, I have made a sketch of the entrance. As seen from Lockyer's observation point, the view is confused by the presence of the fallen no. 55 in the foreground. But by a little study of the subject a sketch can be made as though the fallen stone had been removed. The skyline is now covered with military buildings. Three scales are shown, one of feet, beginning from the right, another of angles of azimuth counting from the north, and the third is a scale of dates in thousands of years. The scale of azimuths gives the angles as seen from Lockyer's observation point, and the scale of dates is calculated from this. On the skyline horizon the middle point $(\mathrm{C})$, is marked. The two directions of the avenue observed by Lockyer are bracketted together; the mean of these is $8 \mathrm{~min} .32 \mathrm{sec}$. north of the middle point. On 26 June 190I, the sun rose close to the Heel stone, as shown, the part below the skyline being dotted. The true horizon is shown by a dotted line. Mr Stone has a somewhat similar diagram, but I differ with him slightly in his deductions from Lockyer's data.

The whole gist of Lockyer's theory is that a long time ago the sun rose at a point in the direction of the avenue, but it does not rise in that direction now. From astronomical knowledge he calculated that the sun rose at this point in I680 B.C., with an allowance of error of 200 years earlier or later.

Now let us consider some of the astronomical facts on which he based his calculations. I have not found, or expected to find, nor am I indeed competent to find any error in them, and in discussing them I have received great help from an astronomical friend. The earth travels in an ellipse, very nearly a circle, round the sun once in a year. Hold a pencil in the usual slanting position, and move your hand round as though you were drawing a large circle, widdershins, or against the hands of a clock. The top of the pencil will point over your shoulder, and will keep pointing in the same direction while your hand moves round. The axis of the earth, in the same way, keeps a slanting position as it goes round the sun, and the north pole points to a part of the sky near the North Star. The axis of the earth is inclined at an angle of about $23 \frac{1}{2}$ degrees from the upright position.

Imagine that you spike an orange on your pencil, and have a candle in the middle of your circle. Half of the orange will be in shadow. While you are moving it away from you on the right hand side of the 


\section{STONEHENGE AS AN ASTRONOMICAL INSTRUMENT}

circle, or when you are moving it towards you on the left hand side, the pencil will be on the edge of the shadow. When the earth is in one of these positions as it moves round the sun, and as it daily turns on its axis, every point will pass through daylight and through night, and the duration of the day will be equal to the duration of the night. These are called the equinoxes, and occur at about 2I March and 23 September, and the sun rises at 6 a.m. and sets at 6 p.m. But while you are moving the pencil sideways, on the part of the circle nearest to you, the upper or north pole of the orange will be in shadow all the time. The middle point of this position is called the winter solstice. At the opposite side of the circle the north pole will always be in the light ; that is the summer solstice. At the equator, sunrise and sunset are at about 6 o'clock all the year round, but at places on the northern hemisphere the daylight will be longer than the night, and the longest day is on about $2 \mathrm{I}$ June.

A little further study of this shows that, as most of us know already, at the equinoxes the sun rises and sets nearly due east and west. In the winter the sun is lower in the sky, its path is cut off at each end, and it rises more towards the south-east and sets toward the south-west. In summer the path is high in the sky and it rises and sets towards the north-east and north-west. The exact point at which it rises in its most northerly position is the only one which concerns us in connexion with Stonehenge.

If the earth had this simple motion, the sunrise points on any one day of the year would be the same year after year for ever. But the axis of the earth does not always point to the same place; it slowly passes from point to point and describes a whole circle in 25,800 years. The North Star is now nearly two and a half moon-breadths away from the present pole in the sky, in a direction opposite to that of the last star but one in the tail of the Great Bear. Some 4,000 years ago a star between the tip of the Great Bear's tail and the North Star, served as a North Star, and in 12,000 years the bright star Vega which is now nearly overhead on a summer evening will be near the pole of the sky.

But besides this, the angle of slope of $23 \frac{1}{2}$ degrees is not exactly fixed, and the angle is about half a degree less than it was 4,000 years ago. The rate at which this angle changes is known now, more exactly than it was in Lockyer's time, and the latest values according to Newcomb are given in Mr Stone's book. The connexion between this angle and the point of sunrise is a matter of rather difficult calculation, but it is easy to see that if the angle were nothing, if the earth's axis 


\section{ANTIQUITY}

were upright as it went round the sun, it would be equinox all the year round, and the sun would always rise in the east. The sloping makes the difference between summer and winter, and (this is the important point) the greater the slope, the more northerly will be the point of sunrise in summer. The result of Newcomb's values as given by $\mathrm{Mr}$ Stone is, that the date at which the sun rose in the direction of Lockyer's axis is I 840 B.C. instead of I 680 B.C.

Three possible moments of sunrise have been mentioned. What we are concerned with are the places of sunrise, the positions of the sun at the first flash, the half-risen sun, and the fully risen sun. In passing from one of these positions to another the sun moves along the path shown by the sloping dotted line. If the half-risen sun had been chosen, the date would have been about 3500 B.C. and the fully risen sun would have touched the skyline at Lockyer's axis in 5200 B.C. Antiquaries consider that 2000 B.C. is a reasonable date, and some competent authorities hold that the early works on the site may have dated from 3000 B.C. or earlier. ${ }^{1}$

Lockyer's assistant, Mr Howard Payn, found, as I have stated, the angle between the tip of the Heel stone and the sunrise point was $8 \mathrm{~min}$. $40 \mathrm{sec}$. Mr Stone discusses the observations, and for some reason which is not clear to me gives (p. r 29) the angle as 20 min. 9 sec. Lockyer states that his axis passes within a few inches of the middle line of the entrance, the deviation being northwards. This deviation worked out from his observations is o deg. $8 \mathrm{~min} .3^{2} \mathrm{sec}$. or 570 years.

As I have said, I agree with $\mathrm{Mr}$ Stone that the middle point of the entrance, between stones nos. 30 and $\mathrm{I}$, is the only one that can be taken for one point on the true axis of Stonehenge. But if you stand alongside the great stone no. 56 on Lockyer's axis, or anyone else's axis, and move your head 5 ins. to the right, and then 5 ins. to the left, you cause the middle point of the entrance to be displaced ro ins., or one sun's breadth relatively to a point on the skyline, and this makes a difference of 2,000 years in the calculated date. You must settle which eye you are going to use, for the difference of position between your right eye and your left makes a difference of 500 years in the date. I do not think that Stonehenge is a very satisfactory astronomical instrument for the purpose of settling dates. If you go to Stonehenge with the midsummer morning crowd, and get a good place with your back to the end of the fallen no. 55, you will see (weather permitting),

1 [The date, or dates, of Stonehenge cannot yet be determined with precision; but, in the opinion of some, 2000 B.C. is too early.--ED.] 


\section{STONEHENGE AS AN ASTRONOMICAL INSTRUMENT}

the sun rise exactly over the Heel stone,-but then you are not on the axis of Stonehenge.

If no better reasons than the foregoing can be adduced to show that Stonehenge was a temple for sun-worship, could any other purpose have been served by its orientation to the sunrise point? Yes: it was perhaps the most simple way of fixing a date in the agricultural calendar. To investigate the capabilities of Stonehenge as a calendar it is necessary to consider the point from which observations might have been taken. Only one point presents itself, namely the centre of the circle. Let us trace the course of the sunrise point from 22 December when it is at its most southerly limit. (The calculation can be very easily made by using an Oxford Astrolabe, made of celluloid and card, designed after the Persian and other medieval instruments by Prof. F. C. Jenkin of The Engineering Laboratory, Parks Road, Oxford). The view of the mid-winter sunrise is cut off by stone no. 52 of the east trilithon. In the middle of March the sunrise point might have been observed between nos. 3 and 4 ; but the sunrise point is moving at its fastest rate. On I April it would have been seen between nos. 2 and 3 if not blocked by a blue stone, and in the middle of May sunrise might be seen between nos. I and 2. It is not worth while to trace the return autumn journey. There are two unhewn boulders and two mounds of earth placed at about $142 \mathrm{ft}$. from the centre. The sun would have risen over one of them on about I February, but the view from the centre would have been blocked by no. 52. Stonehenge was therefore useless for calendar purposes except to fix one date, namely the week (if that can be called a date) of midsummer time.

All this hair-splitting criticism may be applicable to the work of a careful and imaginative astronomer, but is it applicable to such a structure as Stonehenge? I think not. The purpose for which it was built and used still remains a matter of conjecture. Apparently it was never inhabited. It may have been a place of assembly. We may imagine great gatherings for religious ceremonies, or for the administration of justice, or for controversy, or government. It has been regarded as a temple or sacred place. These words originally meant an enclosure, and so far from being a place of assembly, the circle of Stonehenge and the surrounding ditch were, perhaps, to use an expression applicable to primitive religions, $t a b u$, and the general public were excluded from them. The sepulchral character of other lesser stone circles has been established by the discovery in them of cists containing interments. Other suggestions are that it was a monument, 


\section{ANTIQUITY}

that it was a place of execution where defeated British leaders were hanged in honour of Woden, that it was a calendar in stone for the measurement of the solar year, and so on.

There is a widespread popular idea that on the morning of $2 \mathrm{r}$ June something happens at Stonehenge which occurs on no other day of the year, and on that morning the remarkable event is celebrated by chariots, instruments of music, and alcoholic libations, in the form of charabancs, gramophones and beer, to be found there before dawn, and a huge expectant crowd. The builders of Stonehenge may have marked the week, but they could hardly have known the day.

Some calendars tell us which is the shortest day, and one of the leading publishers of diaries has made a mistake about this. It would fall later and later every year did not Leap Year bring it back a whole day. At the end of a century, when Leap Year is omitted, the longest day skips forward from 20 June to 22 June. But the longest day is longer by only a few seconds than the previous or the following day, and this is a matter of rather tedious calculation.

Whitaker's almanack shows that at the latitude of Greenwich in June, the sun rises earlier and earlier until the day comes when it rises at 3.44 a.m. and continues to do so for about a week, and then it rises later. Of course this succession of exactly 44 minutes means that the seconds have been left out. Sunset time is also stationary for several days, and these begin when the fixed sunrise period is ending, because our " mean" time does not correspond with the solar time shown on a sun-dial except on four days in the year. It was impossible that the wise men in the days of the building of Stonehenge, though they knew a good deal of astronomy, could have known anything about this. What they could have done was to observe that the point of sunrise, making long hops in the east in spring, slows down, and creeps to nearly north-east. At last, an observer standing midway under the great trilithon would see it one morning rising close to the north side of the entrance, and its rising point would change less and less each day, and for a period of about three weeks the position of the sun on the horizon at sunrise would move only the width of the sun. The builders doubtless had some such knowledge or had made some such observations before the present arrangement of stones was planned. But to say that this was the purpose and object of Stonehenge seems extravagant. If " sights" to give the most northerly position of the sunrise point were needed, two stones, or two pairs of stones, or two hillocks of earth would have sufficed, and such " sights " are claimed 


\section{STONEHENGE AS AN ASTRONOMICAL INSTRUMENT}

to have been found by Admiral Somerville at Donoughmore, co. Cork, and by Sir Norman Lockyer on Dartmoor.

Archæologists tell us that a considerable number of the primitive huts and long barrows are directed to the north-east, but there is no general orientation of stone circles or avenues in this fashion. Stonehenge as it stands is acknowledged to be one of the most elaborate and perhaps the latest structure of its kind. We find highly skilful dressing of the stones, and it must have been erected by very clever men, perhaps in the way so ably suggested by $\mathrm{Mr}$ Stone. No wonder then, that when they decided to plan so important a work, whether the present structure or some previous one of which we only have traces, and to plan it with reference to the midsummer sunrise, they carried this out carefully. No astronomical knowledge, no calculation, no mathematical instruments, no acquaintance with geometry or surveying was needed. Lockyer brought a theodolite with verniers and magnifiers capable of measuring the 360 degrees of a circle, the 60 minutes of each degree, and the 60 seconds of each minute, and large scale Ordnance maps, observations of the North Star, corrections for the level of the skyline, and for refraction and parallax, in order to make observations on which he might base his estimates of astronomical changes for dating the building. It may be asked :-What did the builders of Stonehenge know of such refinements, and what instruments did they use? There is a confusion here between the objects and intentions. It was indeed a compliment to them that all this was thought necessary. The old builders simply did the work by eye. It is astonishing to find what accurate work can be done by eye with a well-ploughed furrow, or lining up a long straight fence. He would have a rough eye who could not detect a misplacement of 3 ins. at the end of a gardener's line $57 \mathrm{ft}$. long. This is equivalent to a quarter of a degree. If we admit that the builders of Stonehenge could work with half of that error corresponding to a difference of 500 years in the date, what proof have we that they actually did so? There is a manifest probability, but to attempt to produce a proof of the date from the axis of Stonehenge is to argue in a circle.

It is easy to bring all sorts of theories and conjectures now that this grand and simple monument is there. We may prolong the axis to the north-east and find it hits Copenhagen ; or ten and a half miles to the south-west to the village in which I live; and then down to the coast, passing a little to the right of the megaliths of Carnac, and out to sea to the district where the lost Atlantis may have flourished. And we may prolong controversies about it until we fill a library. 